$11-2020$

Sleep and its relation with academic performance among adolescents: An analytical cross sectional study in Gulshan town, Karachi

Zainab Mohammad Anjarwala

Niloufer Sultan Ali

Kashmira Nanji

Anum Arshad Beg

Veena Kumari Karmani

Follow this and additional works at: https://ecommons.aku.edu/pakistan_fhs_mc_fam_med

Part of the Family Medicine Commons 


\title{
Sleep and its relation with academic performance among adolescents: An analytical cross sectional study in Gulshan Town, Karachi
}

Zainab Mohammad Anjarwala', Niloufer Sultan Ali2 ${ }^{2}$ Kashmira Nanji3 , Anum Arshad Beg ${ }^{4}$, Veena Kumari Karmani ${ }^{5}$

\begin{abstract}
Objective: To determine the prevalence of sleep patterns and their relationship with academic performance among adolescents.

Methods: The analytical cross-sectional study was conducted from March to August 2015 in Gulshan Town of Karachi and comprised students in grades 6 to 8 who were selected from six government and private schools. Data was collected regarding their sleeping time, wake-up time, sleep latency and total sleep duration. Paediatric Daytime Sleepiness Scale was administered to calculate daytime sleepiness. Academic performance of students was taken from school academic records. Data was analysed using SPSS 22.

Results: Of the 440 subjects, 234 (53.2\%) were boys and 206 (46.8\%) were girls. The overall age range was 11-16 years. A total of 280 (63.6\%) students had abnormal sleep patterns, 182(41.4\%) suffered from daytime sleepiness, 41 (9.3\%) had abnormal sleep latency and 201 (45.7\%) scored below 60\% in their exams. Among poor sleepers, 157 (56.1\%) scored below $60 \%$ in their exams.

Conclusion: More than half the subjects were found to be sleeping less than required, which eventually affected their academic performance.

Keywords: Adolescents, Sleep patterns, Sleep latency, Daytime sleepiness, Academic performance.
\end{abstract} (JPMA 70: 1948; 2020) DOI: https://doi.org/10.5455/JPMA.25469

\section{Introduction}

Sleep is a basic human need and is considered an important indicator for health and good quality of life at all ages. Several factors can affect the quality of sleep such as work, lifestyle, environment, health and stress. It is defined as a vital component of physical growth and enhancement of the academic performance. ${ }^{1}$ Sleep pattern varies throughout our lives, with most important changes occurring during the initial years as well as during the transition phase from childhood to adolescence. Such changes are partly the result of complex changes that occur in the circadian system and brain maturation. Also, the daily routine, environmental demands and responsibilities change over time and can contribute to the alteration in sleep patterns. ${ }^{2}$

Adolescents with decreased sleep duration suffer from increased daytime sleepiness, daytime fatigue, decreased classroom attention and, hence, decreased academic achievement. 3,4 Moreover, disturbed and poor sleep quality is also associated with low academic performance.5,6 Adolescents require more than 9 hours of sleep each night,

1,4,51,4,5 Department of Family Medicine, Dow Medical College, Dow University of Health Sciences, Karachi, Pakistan; ${ }^{2}$ Department of Family Medicine, Aga Khan University Hospital, Karachi, Pakistan;

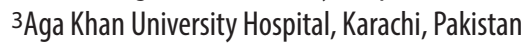

Correspondence: Zainab Mohammad Anjarwala. e-mail: zainab.mohammad@duhs.edu.pk but they usually sleep for only 7.5 to 8.5 hours, with $25 \%$ sleeping for 6.5 hours and only $15 \%$ sleeping for 8.5 hours per night. ${ }^{7}$ The National Sleep Foundation (NSF) recommends 8-10 hours of sleep for teenagers and 7-9 hours of sleep for young adults. 8 Moreover, the results from the 2005-2008 National Health and Nutrition Examination Survey (NHANES) showed $37.1 \%$ of adults in the United States were sleeping $<7$ hours per night and, as a result, $23.2 \%$ had impaired concentration. ${ }^{9}$ Inadequate sleep has negative effect on health, cognition and quality of life of children and adolescents which impacts significantly on social and economic cost. It further effects our learning and memory which is an integral part of achievement in school and academic performance, especially in children and adolescents who are in a developing phase. ${ }^{10}$

A study conducted in Islamabad Medical and Dental College reported $75 \%$ of students sleeping $<6$ hours. ${ }^{11}$ Moreover, $49 \%$ of students from Shifa Medical College, Islamabad, were reported to be sleeping less than required and, as a result, feeling sleepy during lectures (42\%), report daytime fatigue (30\%) and wake up un-refreshed (26\%). ${ }^{12}$ Adolescents aged 0-15 years represent approximately $43.4 \%$ of Pakistan's population. ${ }^{13}$ This figure indicates that large number of adolescents of Pakistan similar to that of other parts of the world are going through a transition phase and are under biological, personal and psychosocial influences that leave them prone to inadequate sleep, irregular sleep-wake schedules and sleep disturbances that 
can in turn affect their academic achievement.

The current study was planned to determine the prevalence of sleep patterns among adolescents and its relation with academic performance.

\section{Subjects and Methods}

The analytical cross-sectional study was conducted in Gulshan Town of Karachi from March to August 2015. After approval from the ethics review committee of Aga Khan University Hospital (AKUH), Karachi, the sample size was calculated using World Health Organisation (WHO) calculator on the basis of least proportion of poor sleep patterns obtained from literature. ${ }^{14}$ After addition of $10 \%$ for non-responders, and while keeping confidence interval (Cl) at $95 \%$ and bound on error $4 \%$, the final sample size was 440 .

The sample was raised using a two-stage stratified random sampling. A list of all secondary schools located in Gulshan Town was obtained from the District Educational Office, and three government and three private schools were selected. Subsequently, students from grades 6-8 aged 1018 years were enrolled on the basis of equal distribution in terms of gender, class and school representation after permission was taken from the principals of the participating schools. The sample was raised from among the children present on the day of data-collection. Those not present on the day were excluded.

Data was collected after a detailed informed consent form was signed by both the students and their parents. A pilot tested questionnaire was filled by the students in 10-15 minutes. The first part of the questionnaire contained students' demographic details, while the second part contained questions assessing the sleep pattern includeing total sleep time (TST), sleep latency and daytime sleepiness.

TST was defined as hours of sleep per night. Normal sleep time was taken as 8-9 hours. ${ }^{15}$ Sleep latency was defined as time to fall asleep and scored 1 if $<15$ minutes, 2 if 15-30 minutes, 3 if 31-60 minutes, and 4 if $>1$ hour. A score of $>3$ was considered abnormal/poor sleep. ${ }^{16}$ In order to calculate TST, time of going to bed and getting up time was inquired. Sleep latency was subtracted from the number of hours spent in bed to work out TST. Daytime Sleepiness was assessed using the Paediatric Daytime Sleepiness Scale (PDSS), a validated self-report measure of sleepiness designed for schoolchildren -aged 11-15 years. 17 Normal sleep pattern was defined as at least 8 sleep hours and PDSS score $<26$ for 6 th and 7 th grades, and $<30$ for the 8 th grade. Abnormal sleep pattern was defined as sleep hours $<8$ hours and PDSS score of $>26$ for 6 th and 7 th grades, and
$>30$ for the 8 th grade.

To determine student's academic achievement, grades and percentages of most recent exam results were accessed from the school academic records with the help of the class teacher, and was considered poor if $<60 \%$ and good if $>60 \%$. A healthy sleep hygiene session on sleep patterns and its relation with academic performance was provided to the teachers at the end of the study.

Data was analysed using SPSS 22. Baseline information on demographics was analysed using descriptive statistics. For continuous variables, means and standard deviation (SD) were reported. For categorical variables, frequencies and percentages was reported. The outcome variables were sleep pattern and academic performance of children. Odds ratio (OR) was calculated to observe the relationship between sleep pattern and academic performance. Stratification was done with respect to age, gender, grade, number of family members, number of rooms, sharing of room, type of school, TST, sleep latency, daytime sleepiness and academic performance. Post-stratification chi-square test was applied. All analyses were two-tailed, and $p<0.05$ was considered statistically significant. Also, univariate analysis was done for normal sleep pattern using various variables. All variables with $p<0.25$ were included in multivariate model and a parsimonious model was developed.

\section{Results}

Of the 440 students, 228(51.8\%) were from government schools and $212(48.2 \%)$ were from private schools. There were 144 (32.7\%) students from grade 6,141 (32\%) from grade 7 and 155(35.2\%) from grade 8 . The age range was 11-16 years. Overall, there were 234 (53.2\%) boys and 206(46.8\%) girls. Of the total, 406 (92.3\%) children were sharing a room with their siblings or family. Daytime sleepiness was observed in 182 (41.4\%) participants and increased sleep latency was observed in 41(9.3\%) (Table 1). Overall, 280 (63.6\%) students had abnormal sleep patterns. Of them, 157 (56.1\%) children had poor academic performance ( $p<0.001$; OR: 3.36; 95\%Cl: 0.19-0.45). Government school, sleep latency and academic performance were significantly related to abnormal sleep patterns $(p<0.05)$ (Table 2).

Age 13 years and good academic performance were positively associated with normal sleep, while less number of rooms was negatively associated with normal sleep (Table 3). 
Table-1: Socio-demographic characteristics.

\begin{tabular}{lc}
\hline Characteristics & $\mathbf{n}(\%)$ \\
\hline Type of school & \\
$\quad$ Government & $228(51.8)$ \\
Private & $212(48.2)$ \\
Family members & \\
2 to 5 & $101(23.0)$ \\
6 to 9 & $260(59.1)$ \\
$10 \&$ above & $79(18.0)$ \\
No. of rooms & \\
1 to 3 & $275(62.5)$ \\
4 to 5 & $134(30.5)$ \\
$6 \&$ above & $31(7.0)$ \\
Room sharing with siblings & \\
Yes & $406(92.5)$ \\
No & $33(7.5)$ \\
Sleep latency & \\
$<15$ mins & $188(42.7)$ \\
$15-60$ mins & $211(48.0)$ \\
$>60$ mins & $41(9.3)$ \\
Academic performance & \\
Poor $(<60 \%)$ & $201(45.7)$ \\
Good (>60\%) & $239(54.3)$ \\
\hline
\end{tabular}

\section{Discuss ion}

As per the findings, 154 (55\%) of the adolescents going to government schools had abnormal sleep patterns compared to 126 (45\%) of those going to private schools $(p=0.048)$, which could be likely due to the diversity of socio-demographic characteristics of the students of the two groups. Due to the social and demographic culture of Pakistan, majority of the adolescents were sharing room with siblings or family members, and it was assumed that sharing a room would result in increased distraction and, hence, decrease sleep duration. However, no significant association was seen between the two $(p>0.05)$.

Overall, $63.6 \%$ of our subjects had abnormal sleep pattern and increased daytime sleepiness. These results are consistent with $72.6 \%$ among Hong Kong adolescents, 18 and $65 \%$ in Saudi Arabia. ${ }^{19}$ Similarly, recommended sleeping hours for adolescents is 9 hours with $70 \%$ of high school students in United States sleeping $<8$ hours. ${ }^{20}$ The significance of this result can be better understood in the light of another study conducted in Karachi about the lifestyle and health behaviours of adolescents aged 12-18 years which showed similar results with $58.9 \%$ of the participants sleeping $<8$ hours. ${ }^{21}$

Daytime sleepiness was observed in $41.4 \%$ subjects which was consistent with results reported from Saudi Arabia $37 \%{ }^{19}$ and Hong Kong 38.7\%. ${ }^{18}$

Regarding sleep latency, 104(65\%) of the normal sleepers took $<15$ minutes to fall asleep $(p<0.05)$. This association
Table-2: Stratification of sleep pattern according to socio-demographic characteristics and academic performance

\begin{tabular}{|c|c|c|c|}
\hline Characteristics & $\begin{array}{c}\text { Normal } \\
\text { sleep pattern } \\
\mathbf{n}(\%)\end{array}$ & $\begin{array}{c}\text { Abnormal } \\
\text { sleep pattern } \\
\text { n (\%) }\end{array}$ & $p$ value \\
\hline \multicolumn{4}{|l|}{ Gender } \\
\hline Male & $91(58.9)$ & $143(51.1)$ & \multirow[t]{2}{*}{0.141} \\
\hline Female & $69(43.1)$ & $137(48.9)$ & \\
\hline \multicolumn{4}{|l|}{ Age (years) } \\
\hline 11 & $25(15.6)$ & $35(12.5)$ & \multirow[t]{4}{*}{0.1} \\
\hline 12 & $39(24.4)$ & $46(16.4)$ & \\
\hline 13 & $43(26.9)$ & $82(29.3)$ & \\
\hline 14\& above & $53(33.1)$ & $117(41.8)$ & \\
\hline \multicolumn{4}{|l|}{ Grade } \\
\hline 6 & $59(36.9)$ & $85(30.4)$ & \multirow[t]{3}{*}{0.361} \\
\hline 7 & $47(29.4)$ & $94(33.6)$ & \\
\hline 8 & $54(33.8)$ & $101(36.1)$ & \\
\hline \multicolumn{4}{|l|}{ Type of school } \\
\hline Government & $74(46.3)$ & $154(55)$ & \multirow[t]{2}{*}{0.048} \\
\hline Private & $86(53.8)$ & $126(45 \%)$ & \\
\hline \multicolumn{4}{|c|}{ Family members } \\
\hline 2 to 5 & $41(25.6)$ & $60(21.4)$ & \multirow[t]{3}{*}{0.541} \\
\hline 6 to 9 & $93(58.1)$ & $167(59.6)$ & \\
\hline $10 \&$ above & $26(16.3)$ & $53(18.9)$ & \\
\hline \multicolumn{4}{|l|}{ No. of rooms } \\
\hline 1 to 3 & $108(67.5)$ & $167(59.6)$ & \multirow[t]{3}{*}{0.107} \\
\hline 4 to 5 & $39(24.4)$ & $95(33.9)$ & \\
\hline $6 \&$ above & $13(8.1)$ & $18(6.4)$ & \\
\hline \multicolumn{4}{|c|}{ Room sharing with siblings } \\
\hline Yes & $145(90.6)$ & 261 (93.2) & \multirow[t]{2}{*}{0.402} \\
\hline No & $15(9.4)$ & $18(6.4)$ & \\
\hline \multicolumn{4}{|l|}{ Sleep latency } \\
\hline$<15 \min$ & $104(65)$ & $84(30)$ & \multirow[t]{3}{*}{$<0.001^{*}$} \\
\hline $15-60 \mathrm{~min}$ & $51(31.9)$ & $150(57.1)$ & \\
\hline$>60$ mins & $5(3.1)$ & $36(12.9)$ & \\
\hline \multicolumn{4}{|c|}{ Academic performance } \\
\hline Poor $(<60 \%)$ & $44(27.6)$ & $157(56.1)$ & \multirow[t]{2}{*}{$<0.001^{*}$} \\
\hline $\operatorname{Good}(>60 \%)$ & $116(72.5)$ & $123(43.9)$ & \\
\hline
\end{tabular}

Table-3: Multivariate analysis of normal sleep pattern according to various characteristics.

\begin{tabular}{lcccc}
\hline Characteristics & a0R & \multicolumn{2}{c}{$95 \%$ Cls } & p-value \\
\hline $\begin{array}{l}\text { Gender } \\
\text { Female }\end{array}$ & Ref & & & \\
$\quad \begin{array}{l}\text { Male } \\
\text { Age (years) }\end{array}$ & 1.413 & 0.926 & 2.157 & 0.109 \\
11 & & & & \\
12 & Ref & & & \\
13 & 1.425 & 0.744 & 2.730 & 0.286 \\
14 \& above & 2.048 & 1.131 & 3.711 & 0.018 \\
No. of rooms & 1.083 & 0.638 & 1.841 & 0.767 \\
1 to 3 & & & & \\
4 to 5 & 0.426 & 0.258 & 0.704 & 0.001 \\
6\& above & 0.859 & 0.385 & 1.916 & 0.710 \\
Academic performance & Ref & & & \\
$\quad$ Poor (<60\%) & Ref & & & \\
Good (>60\%) & 4.013 & 2.583 & 6.234 & 0.000 \\
\hline aOR: Adjusted odds ratio; Cl: Confidence interval. & & &
\end{tabular}

aOR: Adjusted odds ratio; Cl: Confidence interval. 
likely indicates that children who tend to sleep within 15 minutes of going to bed have increased chances of having normal sleep duration and good academic performance. These results were similar to those reported from among Sudanese medical students who had a sleep latency of 14.8 minutes with excellent school performance. 22

In terms of limitation, the current study did not identify several factors like parental education, media usage and chronic illnesses that affect sleep patterns among adolescents. Further studies are needed on a larger scale with in-depth assessment of factors causing sleep problems and their relation with other health problems to provide further advice to parents, teachers and health policy-makers.

\section{Conclusion}

More than half the children having an abnormal sleep pattern had poor academic performance. There is a need to generate awareness among the youth regarding the importance of healthy night-time sleep in order to effectively function during the day which in the long term improves memory and concentration, eventually improving academic performance.

\section{Disclaimer: None. \\ Conflict of Interest: None. Source of Funding: None.}

\section{References}

1. Sahin S, Ozdemir K, Unsal A, Temiz N. Evaluation of mobile phone addiction level and sleep quality in university students. Pak J Med Sci 2013; 29: 913-8.

2. Barclay NL, Gregory AM. Sleep in Childhood and Adolescence: AgeSpecific Sleep Characteristics, Common Sleep Disturbances and Associated Difficulties. The Neurobiology of Childhood: Curr Top Behav Neurosci 2014; 16: 337-65.

3. Khan UA, Pasha SN, Khokhar SK, Rizvi AA. Sleep habits and their consequences: a survey. Rawal Med J 2004; 29: 3-7.

4. Perez-Lloret S, Videla AJ, Richaudeau A, Vigo D, Rossi M, Cardinali DP, et al. A multi-step pathway connecting short sleep duration to daytime somnolence, reduced attention, and poor academic performance: an exploratory cross-sectional study in teenagers. J Clin Sleep Med 2013; 9: 469-73.

5. El Hangouche AJ, Jniene A, Aboudrar S, Errging L, Rkain H, Cherti M, et al. Relationship between poor quality sleep, excessive daytime sleepiness and low academic performance in medical students. Adv Med Educ Pract 2018; 9: 631-8.

6. Schmidt RE, Van der Linden M. The relations between sleep, personality, behavioral problems, and school performance in adolescents. Sleep Med Clin 2015; 10: 117-23.

7. Moore M, Meltzer LJ. The sleepy adolescent: causes and consequences of sleepiness in teens. Paediatr Respir Rev 2008; 9: 114-21

8. Hirshkowitz M, Whiton K, Albert SM, Alessi C, Bruni O, DonCarlos L, et al. National Sleep Foundation's sleep time duration recommendations: methodology and results summary. Sleep Health 2015; 1: 40-3.

9. Centers for Disease Control and Prevention (CDC). Effect of short sleep duration on daily activities--United States, 2005-2008. MMWR Morb Mortal Wkly Rep 2011; 60: 239-42.

10. Shochat T, Cohen-Zion M, Tzischinsky O. Functional consequences of inadequate sleep in adolescents: a systematic review. Sleep Med Rev 2014; 18: 75-87.

11. Afzal M, Rizvi F. Sleep pattern and sleep duration of medical college students. Ann Pak Inst Med Sci 2011; 7: 79-81.

12. Khan UA, Pasha SN, Khokhar SK, Rizvi AA. Sleep habits and their consequences: a survey. Rawal Med J 2004; 29: 3-7.

13. Pakistan Bureau of Statistics, Government of Pakistan. Demographic indicators- 1998 census. [Online]. July 2019 [Cited 2019 July 07]. Available from: URL: http://www.pbs.gov.pk/content/demographic-indicators-1998-census

14. Lwanga SK, Lemeshow $S$, sample size determination in health studies, A practical manual. World Health Organization. [Online] 1991 [Cited 2019 May 20]. Available from: URL: https://apps.who.int/ iris/handle/10665/40062

15. Liu X, Liu L, Owens JA, Kaplan DL. Sleep patterns and sleep problems among schoolchildren in the United States and China. Pediatrics 2005; 115: 241-9.

16. Liu X, Zhao Z, Jia C, Buysse DJ. Sleep patterns and problems among Chinese adolescents. Pediatrics 2008; 121: 1165-73.

17. Drake C, Nickel C, Burduvali E, Roth T, Jefferson C, Pietro B. The pediatric daytime sleepiness scale (PDSS): Sleep habits and school outcomes in middle school children. Sleep 2003; 26: 455-8

18. Mak KK, Lee SL, Ho SY, Lo WS, Lam TH. Sleep and academic performance in Hong Kong adolescents. J Sch Health 2012; 82: 522-7.

19. Merdad RA, Merdad LA, Nassif RA, El-Derwi D, Wali SO. Sleep habits in adolescents of Saudi Arabia; distinct patterns and extreme sleep schedules. Sleep Med 2014; 15: 1370-8.

20. Perry GS, Patil SP, Presley-Cantrell LR. Raising awareness of sleep as a healthy behavior. Prev Chronic Dis 2013; 10:1-4.

21. Qidwai W, Ishaque S, Shah S, Rahim M. Adolescent lifestyle and behaviour: a survey from a developing country. PLoS One 2010; 5: e12914.

22. Mirghani HO, Mohammed OS, Almurtadha YM, Ahmed MS. Good sleep quality is associated with better academic performance among Sudanese medical students. BMC Res Notes 2015; 8: 706. 